\title{
$\mathrm{M}|\mathrm{R}| \mathrm{S}$ Internet Journal Nitride Semiconductor Research
}

\section{Modeling GaN Growth by Plasma Assisted MBE in the Presence of Low Mg Flux}

\author{
Nathan Sipe ${ }^{1}$ and Rama Venkat ${ }^{1}$ \\ ${ }^{1}$ University of Nevada, Las Vegas,
}

(Received Wednesday, August 15, 2001; accepted Wednesday, January 16, 2002)

\begin{abstract}
A rate equation model is developed to investigate the plasma assisted MBE growth of GaN in the presence of a fractional monolayer of $\mathrm{Mg}$. Four distinct cases were identified and modeled - (i) Galimited regime (ii) Low $\mathrm{N}$-limited regime (iii) Medium $\mathrm{N}$-limited regime and (iv) High $\mathrm{N}$-limited regime. In the model, it is assumed that $\mathrm{Ga}$ arriving on a $\mathrm{Mg}$ site undergoes faster incorporation into the epilayer through an exchange reaction compared to $\mathrm{Ga}$ arriving directly on a $\mathrm{N}$ surface.

Additionally the incorporation rate of $\mathrm{Ga}$ was assumed to depend on the size of the Ga cluster. The results of the model are in good agreement with that of experiments. The non-monotonic behavior of growth rate with Ga flux for moderate $\mathrm{Mg}$ coverage is explained based on the incorporation rate dependence of $\mathrm{Ga}$ on the cluster size.
\end{abstract}

\section{Introduction}

Group III nitrides are important for many opto-electronic devices. The future technologies based on microelectronic devices such as blue light emitting diodes, ultra-violet lasers for high capacity storage devices, and high temperature, high field heterojunction bipolar devices depend on these materials [1]. One method of producing III-nitride based device structures is molecular beam epitaxy. The understanding of the surface kinetics of the growth processes in molecular beam epitaxy is limited despite active experimental research. Thorough understanding of the growth process will help realize reliable production of high quality material in large quantities, which in turn will help in commercializing III-nitride based devices.

In order to make useful solid-state devices, a p-type dopant must be identified. Mg with its thermal activation energy of $\sim 200 \mathrm{meV}$, is the most suitable candidate at the current level of technology [2]. It is, therefore, important to understand the influence of $\mathrm{Mg}$ on the surface kinetics of the GaN MBE growth process. In addition to acting as a p-type dopant, $\mathrm{Mg}$ has the benefit of inhibiting Ga droplet formation under N-limited conditions in the MBE growth of GaN [3]. Ga droplets get incorporated into the growing epilayer as pockets of $\mathrm{Ga}$, thus resulting in poorer quality materials [4]. For high Mg fluxes resulting in $1 / 4$ to $1 / 2$ monolayer (ML) surface coverage, the $\mathrm{Mg}$ incorporates into the epilayer [2]. However, increasing $\mathrm{Mg}$ above $1 \mathrm{ML}$ results in reversal from Ga-polarity surface to N-polarity surface and in lower $\mathrm{Mg}$ incorporation [5]. $\mathrm{Mg}$ has a much different behavior below $1 / 4 \mathrm{ML}$ surface coverage. At a low $\mathrm{Mg}$ flux, the growth rate increases up to $30 \%$ for addition of $\mathrm{Mg}$ up to $1 / 4 \mathrm{ML}$ [3]. Improved growth rates are necessary for producing high yield of material in a short amount of time.

Daudin et al. [3] found three different types of growth behaviors for three different coverages of $\mathrm{Mg}$ on the surface $\left(\mathrm{C}_{\mathrm{Mg}}\right)$. When $\mathrm{C}_{\mathrm{Mg}}=0$, the growth rate increases as a function of $\mathrm{Ga}$ flux in the $\mathrm{Ga}$ limited regime, then saturates at a constant value in the N-limited regime. For $\mathrm{C}_{\mathrm{Mg}}=0.05 \mathrm{ML}$, the growth rate increases until a critical Ga flux and then decreases rapidly until another critical $\mathrm{Ga}$ flux beyond which it increases and saturates

In spite of several experimental studies on the influence of $\mathrm{Mg}$ on GaN crystal quality of growth, the mechanisms of the growth are not well understood. In this article, a rate equation model based on the kinetics of the surface processes is presented (in section 2). In section 3, the results of the model are presented and compared with the experimental data of Daudin et al. [3]. Conclusions of the model are presented in section 4 . 


\section{Model}

\subsection{Experimental Observations used in the Model}

The following experimental results form the basis of the model developed in the study.

i) $\mathrm{Mg}$ incorporates into the epilayer for flux values corresponding to a cell temperature of $\mathrm{T}_{\mathrm{Mg}}=250^{\circ} \mathrm{C}$ and above [2].

ii) GaN growth rate increases with $\mathrm{T}_{\mathrm{Mg}}$ in the Ga-limited regime of growth with a $30 \%$ increase for a change from no $\mathrm{Mg}$ present to $\mathrm{T}_{\mathrm{Mg}}=230^{\circ} \mathrm{C}$ [3].

iii) $\mathrm{GaN}$ growth rate reaches a constant value with $\mathrm{Ga}$ flux in the $\mathrm{N}$-limited regime for no $\mathrm{Mg}$ and $\mathrm{T}_{\mathrm{Mg}}=$ $230^{\circ} \mathrm{C}$ with a higher growth rate for $\mathrm{T}_{\mathrm{Mg}}=230^{\circ} \mathrm{C}$ [3].

iv) The growth rate decreases drastically in the initial portion of $\mathrm{N}$-limited regime and then increases and reaches a constant value for $\mathrm{T}_{\mathrm{Mg}}=212^{\circ} \mathrm{C}$ [3].

v) Fewer larger $\mathrm{Ga}$ droplets were found in the presence of $\mathrm{Mg}$ compared to larger number of smaller $\mathrm{Ga}$ droplets when residual $\mathrm{Mg}$ was present [3].

vi) $\mathrm{Mg}$ segregates to the surface for low Ga coverage cases [6].

vii) $\mathrm{Mg}$ increases the surface migration rate of $\mathrm{Ga}$ on the surface [2].

viii) $\mathrm{Mg}$ on $\mathrm{N}$ passivates the $\mathrm{N}$ surface, preventing the formation of N-N complexes on the surface [3].

\subsection{Theoretical Model}

The rate equation model is based on the experimental observations listed in section 2.1 and is similar to the one developed for the GaN MBE growth using Ammonia and ECR N-plasma [7] [8], except that in the present model substrate temperature dependence is not considered. The experimental observations listed in 2.1 necessitate the use of four cases based on the $\mathrm{Mg}$ surface coverage.

2.2.1 Case 1: ( Ga-limited regime) $\left(\mathrm{C}_{\mathrm{Ga}}<\mathrm{C}_{\mathrm{N}}\right)$

In this case, $\mathrm{Ga}$ can arrive on two possible surfaces; $\mathrm{Mg}$ or $\mathrm{N}$. The Ga arriving on $\mathrm{Mg}$ surface is assumed to undergo a surface exchange mechanism to incorporate into the epilayer, thus allowing $\mathrm{Mg}$ to ride to the surface. The Ga will incorporate into the epilayer on the exposed $\mathrm{N}$ surface as well. Additionally, evaporation of Ga from the surface was also allowed. Pictorially, these processes are shown in Figure 1a. Mathematically, time evolution of the surface coverage of Ga based on the surface processes can be modeled as:

$$
\frac{d C_{G a}}{d t}=J_{G a}-\frac{\left(C_{N}-C_{M g}\right)^{2} * C_{G a}}{C_{N}^{*} \tau_{1}}-\frac{C_{M g}{ }^{2} * C_{G a}}{C_{N}^{*} \tau_{2}}-\frac{C_{G a}}{t_{3}}
$$

where $\mathrm{C}_{\mathrm{Ga}}, \mathrm{C}_{\mathrm{Mg}}$, and $\mathrm{C}_{\mathrm{N}}$ are surface coverages of $\mathrm{Ga}, \mathrm{Mg}$ and $\mathrm{N}$ respectively. $\mathrm{C}_{\mathrm{Ga}}+\mathrm{C}_{\mathrm{Mg}}$ in a layer is always less than or equal to 1.0. Anytime that $\mathrm{C}_{\mathrm{Ga}}$ exceeds 1.0, the excess $\mathrm{Ga}$ forms droplets over the layer as shown in Figure 1b. The terms on the R.H.S. describes the change in $\mathrm{Ga}$ surface coverage due to $\mathrm{Ga}$ flux, incorporation of $\mathrm{Ga}$ on the $\mathrm{N}$ surface, the incorporation of $\mathrm{Ga}$ due to $\mathrm{Mg}$, and the evaporation of $\mathrm{Ga}$, respectively. In the second term, the coverage of $\mathrm{N}$ available for $\mathrm{Ga}$ to incorporate is $\left(C_{N}-C_{\text {Mg }}\right)$ and the fraction of $\mathrm{Ga}$ available for incorporation through direct incorporation is $\left(\frac{C_{N}-C_{M g}}{C_{N}}\right) * C_{G a}$. In the third term, the available surface to incorporate through the $\mathrm{Mg}$ is $\mathrm{C}_{\mathrm{Mg}}$ and the fraction of $\mathrm{Ga}$ available to incorporate through $\mathrm{Mg}$ is $\frac{C_{\mathrm{Mg}}}{C_{N}} *\left(C_{G a}\right)$.

At the steady state $\frac{d C_{G a}}{d t}$ is equal to zero. Solving for $\mathrm{C}_{\mathrm{Ga}}$, we get:

$$
C_{G a}=\frac{J_{G a}}{\frac{\left(C_{N}-C_{M g}\right)^{2}}{C_{N}^{*} \tau_{1}}+\frac{C_{M G}^{2}}{C_{N}^{*} \tau_{2}}+\frac{1}{\tau_{3}}}
$$

From Equation (1.2) the growth rate is:

$$
G=C_{G a} *\left(\frac{\left(C_{N}-C_{M g}\right)^{2}}{\tau_{1} * C_{N}}+\frac{C_{M g}^{2}}{\tau_{2} * C_{N}}\right)
$$

\subsubsection{Case 2:( Low $\mathrm{N}$-limited regime) $\mathrm{C}_{\mathrm{Ga}}>\mathrm{C}_{\mathrm{N}}$ and} $\left(\mathrm{C}_{\mathrm{Ga}}-\mathrm{C}_{\mathrm{N}}\right)<\mathrm{C}_{\mathrm{Mg}}$

Case 2 occurs when the Ga coverage exceeds the $\mathrm{N}$ coverage by a small value. In this case, there is excess $\mathrm{Ga}$ on the surface as shown in Figure 1b. Since, experimentally it is known that $\mathrm{Mg}$ causes $\mathrm{Ga}$ agglomeration, it is assumed that the excess Ga agglomerates only on the $\mathrm{Mg}$ sites. Thus on the $\mathrm{Mg}$ sites, a second layer of $\mathrm{Ga}$ fills partially on top of the first Ga layer. In the model, it is assumed that due to buildup of two layers of $\mathrm{Ga}$, exchange of the two-layer portion of $\mathrm{Ga}$ with $\mathrm{Mg}$ is prevented due to $\mathrm{Ga}-\mathrm{Ga}$ bonding. Thus, as $\mathrm{Ga}$ arrives in excess, the second layer coverage of $\mathrm{Ga}$ increases and the Mg-Ga exchange decreases and thus, decreasing the overall GaN growth rate. Mathematically, these observations can be modeled in terms of the time evolution of Ga as: 


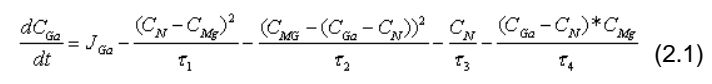

The terms on the R.H.S. represent the coverage change due to $\mathrm{Ga}$ flux, the incorporation of $\mathrm{Ga}$ onto the $\mathrm{N}$ surface, the incorporation of $\mathrm{Ga}$ through the $\mathrm{Ga}-\mathrm{Mg}$ exchange, $\mathrm{Ga}$ evaporation, and $\mathrm{Ga}$ droplet formation, respectively. At steady state, $\mathrm{C}_{\mathrm{Ga}}$ can be obtained as:

.2)

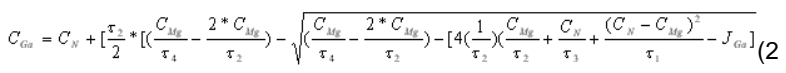

From Equation (2.2), the growth rate equation is obtained as:

$$
G=\frac{\left(C_{N}-C_{M g}\right)^{2}}{\tau_{1}}+\frac{\left[C_{M g}-\left(C_{G a}-C_{N}\right)\right]^{2}}{\tau_{2}}
$$

\subsubsection{Case 3: (Medium N-limited): $\left(\mathrm{C}_{\mathrm{Ga}}>\mathrm{C}_{\mathrm{N}}\right)$ and $\left(\mathrm{C}_{\mathrm{Ga}}\right.$} $\left.\left.-\mathrm{C}_{\mathrm{N}}\right)>\mathrm{C}_{\mathrm{Mg}}\right)$ )

Case 3 occurs when $\mathrm{C}_{\mathrm{Ga}}$ exceeds $\left(\mathrm{C}_{\mathrm{N}}+\mathrm{C}_{\mathrm{Mg}}\right)$. In this case, the excess $\mathrm{Ga}$ produces a strain on the epilayer that forces the Mg to segregate to the surface. Two competing processes exist according to the site of arrival of $\mathrm{Ga}$, either on top of $\mathrm{Mg}$ or on top of $\mathrm{Ga}$ droplets, as depicted in Figure 1c. The incorporation of $\mathrm{Ga}$ into the epilayer by $\mathrm{Mg}$ occurs at a faster rate than $\mathrm{Ga}$ incorporating into the droplets. Mathematically, the rate equation for $\mathrm{C}_{\mathrm{Ga}}$ is:

$$
\frac{d C_{G a}}{d t}=J_{G a}-\frac{\left(C_{N}-C_{M g}\right)^{2}}{\tau_{1}}-\frac{\left(C_{M g}-\left(C_{G a}-C_{N}\right)\right)^{2}}{\tau_{2}}-\frac{C_{N}}{\tau_{3}}-\frac{C_{M g}{ }^{2}}{\tau_{4}}
$$

Equation (3.1) is similar to Equation (2.1) except that in this case $\mathrm{C}_{\mathrm{Ga}}-\mathrm{C}_{\mathrm{N}}=\mathrm{C}_{\mathrm{Mg}}$, which physically means that the droplet formation occurs only over the area occupied by $\mathrm{Mg}$.

Under steady-state,

$$
C_{G a}=C_{N}+C_{M g}+\tau_{2} * \sqrt{J_{G a}-\frac{C_{N}}{\tau_{3}}-\frac{C_{M g}{ }^{2}}{\tau_{4}}-\frac{\left(C_{N}-C_{M g}\right)^{2}}{\tau_{1}}}
$$

The growth rate is, $\mathrm{G}$, is given by:

$$
G=\frac{\left(C_{N}-C_{M g}\right)^{2}}{\tau_{1}}+\frac{\left(C_{M g}-\left(C_{G a}-C_{N}\right)\right)^{2}}{\tau_{2}}
$$

\subsubsection{Case 4: (High N-limited) $\mathrm{C}_{\mathrm{Ga}}>\mathrm{C}_{\mathrm{N}}+2 \mathrm{C}_{\mathrm{Mg}}$}

In this case, the $\mathrm{Ga}$ droplet on top of the $\mathrm{Mg}$ layer completely separates out leaving a $\mathrm{Mg}$ layer completely covered with a single Ga layer all the time. All excess Ga agglomerates with the already existing Ga droplet or evaporates. These processes are pictorially shown in Figure 1d. Mathematically, the growth rate is dependent only on $\mathrm{C}_{\mathrm{N}}$ and $\mathrm{C}_{\mathrm{Mg}}$ and is given by:

$$
G=\frac{\left(C_{N}-C_{M g}\right)^{2}}{\tau_{1}}+\frac{C_{M g}^{2}}{\tau_{2}}
$$

where the terms on the R.H.S. describes contributions to the growth rate due to the incorporation of $\mathrm{Ga}$ on $\mathrm{N}$, and the incorporation of $\mathrm{Ga}$ through the $\mathrm{Ga}-\mathrm{Mg}$ exchange, respectively.

Equations 1.1-4.1 were programmed in $\mathrm{C}++$ language and the computation of $\mathrm{G}$ as a function of $\mathrm{Ga}$ flux and $\mathrm{Mg}$ coverage were performed on a computer with a $450 \mathrm{MHz}$ AMD K6-2 processor.

Growth Rate given by Eqn. 1.3-2.3 (Case 1 and Case 2), Eqn 2.3 -3.3 (Case 2 and Case 3), and Eqn. 3.3-4.1 (Case 3 and Case 4), are equal at Case 1-2, Case 2-3, Case 3-4 limits, respectively.

\section{Results and Discussion}

The relationship between Ga flux in ML/s and the $\mathrm{Ga}$ cell temperature, $\mathrm{T}_{\mathrm{Ga}}$, was obtained by comparing the data of Figure 1 of Ref. [9] and Figure 6.(a) of Ref. [3]. Thus, the experimental growth rate, $\mathrm{G}$, versus $\mathrm{T}_{\mathrm{Ga}}$ data of Ref. [9] can be converted to growth rate, $\mathrm{G}$, versus $\mathrm{Ga}$ flux, $\mathrm{J}_{\mathrm{Ga}}$. Similarly a quantitative relationship between the magnesium cell temperature, $\mathrm{T}_{\mathrm{Mg}}$, and coverage of the surface riding $\mathrm{Mg}, \mathrm{C}_{\mathrm{Mg}}$, was established using experimental data of Daudin et al. [3] and used in the model. The model parameters, time constants for the various mechanisms, $\tau_{2}, \tau_{3}$, and $\tau_{4}$, were found to be dependent on the $\mathrm{C}_{\mathrm{Mg}}$ by fitting the experimental data with that of our results. The dependence of the time constants on the $\mathrm{C}_{\mathrm{Mg}}$ is presented in Table. In general, $\tau_{1}, \tau_{2}$, and $\tau_{4}$ decreased as $\mathrm{C}_{\mathrm{Mg}}$ increased, $\tau_{3}$ increased with $\mathrm{C}_{\mathrm{Mg}}$.

The growth rate, $G$, versus Ga flux, for the case of no $\mathrm{Mg}$ present was obtained using Equations 1.2-1.3 and is shown in Figure 2 along with the experimental data. For all growth vs. Ga flux curves several data points were computed for each case. But for purposes of clarity only 
the growth curve is shown. The agreement between the results is excellent. The growth rate increases linearly with the $\mathrm{J}_{\mathrm{Ga}}$ in the Ga limited regime and saturates at a constant value in the $\mathrm{N}$-limited regime as expected. The saturation growth rate corresponds to a sticking coefficient of 0.805 .

For the cases of residual $\mathrm{Mg}$ and $\mathrm{T}_{\mathrm{Mg}}$ equal to $212^{\circ} \mathrm{C}$, and $220^{\circ} \mathrm{C}$, the surface coverage of $\mathrm{Mg}$ can be estimated qualitative to be $0.05,0.1$, and 0.15 , from experimental data of Daudin et al. [3] respectively. With these values of $\mathrm{Mg}$ surface coverages, growth rate, $\mathrm{G}$, versus $\mathrm{Ga}$ flux, $\mathrm{J}_{\mathrm{Ga}}$, plots were obtained using Equation 1.2, 1.3, 2.2, 2.3, and 4.1.and are shown in Figures 2-5 along with the corresponding experimenta1 data [3]. In all three cases, the qualitative agreement between the experimental and theoretical plots is good. Quantitative agreement is only fair due to uncertainty and scatter in the experimental data and in the model parameters.

For the case of residual $\mathrm{Mg}$, the growth rate is linear with $\mathrm{J}_{\mathrm{Ga}}$ in the Ga-limited regime similar to the $\mathrm{C}_{\mathrm{Mg}}=0$ case, except that in this case, due to faster incorporation of $\mathrm{Ga}$ through $\mathrm{Ga}-\mathrm{Mg}$ exchange as described in 2.1, the growth rate is faster. In the low N-limited regime described in 2.2, the growth rate decreases with $\mathrm{J}_{\mathrm{Ga}}$ given by Equations 2.2 and 2.3. The reason for this observed behavior is as follows. As the Ga coverage, $\mathrm{C}_{\mathrm{Ga}}$, becomes more than the $\mathrm{N}$ coverage, $\mathrm{C}_{\mathrm{N}}$, there is excess available Ga. Presence of $\mathrm{Mg}$ makes the Ga coalesce on the $\mathrm{Mg}$ sites, which results in stronger bonding between $\mathrm{Ga}-\mathrm{Ga}$ resulting in less $\mathrm{Ga}-\mathrm{Mg}$ exchange. This will result in a decrease in Ga incorporation with the decrease directly proportional to the excess Ga. At a certain $\mathrm{J}_{\mathrm{Ga}}$, the excess $\mathrm{Ga}$ is exactly equal to the coverage of $\mathrm{Mg}$ at which point the growth rate reaches a minimum, which is below the saturated growth rate of the $\mathrm{C}_{\mathrm{Mg}}=0$ case. When the excess $\mathrm{Ga}$ exceeds the coverage of $\mathrm{Mg}$, the $\mathrm{Mg}$ escapes the cluster leaving a ball of $\mathrm{Ga}$ and any more excess Ga partly exchanges with $\mathrm{Mg}$ or evaporates or agglomerates with the Ga droplet. Thus, the growth rate increases with further increase in $\mathrm{J}_{\mathrm{Ga}}$ and saturates at a fixed value dictated by the maximum Mg-Ga exchange rate.

In this model, the growth rate dependence on substrate temperature, surface reconstructions, or the growth surface polarity, are not considered. If detailed

experimental data for various conditions are available, then a similar model can be adopted and time constants can be obtained by fitting the experimental data to theoretical data. Using the temperature dependence of time constants, activation energies for the various surface processes can be obtained.

\section{Conclusion}

A rate equation model is developed to investigate the plasma assisted MBE growth of $\mathrm{GaN}$ in the presence of fractional monolayer of $\mathrm{Mg}$. Four distinct cases for the model based on the surface processes were identified (i) Ga-limited regime (ii) Low N-limited regime (iii) Medium N-limited regime and (iv) High N-limited regime. The results of the model were found to be in good agreement with the experimental results of Daudin et al [2]. It is found that exchange between $\mathrm{Ga}$ and $\mathrm{Mg}$ produces a faster growth rate. Additionally, it is found that non-monotonic behavior of growth rate with $\mathrm{Ga}$ flux results due to the dependence of the exchange mechanism Ga cluster size.

\section{ACKNOWLEDGMENTS}

This work was supported by AFOSR DEPSCoR 99 under the grant \# F49620-99-1-0188 under program manager Dr. Jerry Witt.

\section{REFERENCES}

[1] H. Morkoc, Mat. Sci. Eng. Rep. 33, 135-207 (2001).

[2] A. J. Ptak, T. H. Meyers, L. T. Romano, C. G. Van de Walle, J. E. Northrup, unpublished.

[3] B. Daudin, G. Mula, P. Peyla, Phys. Rev. B 61, 10330 (2000).

[4] B. Daudin, G. Feuillet, Guido Mula, H. Mariette, J. L. Rouviere, N. Pelekanos, G. Fishman, C. Adelmann, J. Simon, Phys. Stat. Sol. A 176, 261 (1999).

[5] V. Ramachandran, R. M. Feenstra, W. L. Sarney, L. Salamanca-Riba, J. E. Northrup, L. T. Romano, D. W. Greve, Appl. Phys. Lett. 75, 808 (1999).

[6] T. S. Cheng, S. V. Novikov, C. T. Foxon, J. W. Orton, Sol. St. Comm. 109, 439-443 (1999).

[7] Wenning Fu, Rama Venkat, J. Vac. Sci. Technol. B 18, 1467 (2000).

[8] S. MuthuVenkatraman, Suresh Gorantla, Rama Venkat, Donld L. Dorsey, J. Electron. Mater. 27, 472 (1998).

[9] G. Mula, B. Daudin, P. H. Peyla, Phys. Stat. Sol. A 176, 385 (1999).

\section{FIGURES \\ FIGURES}




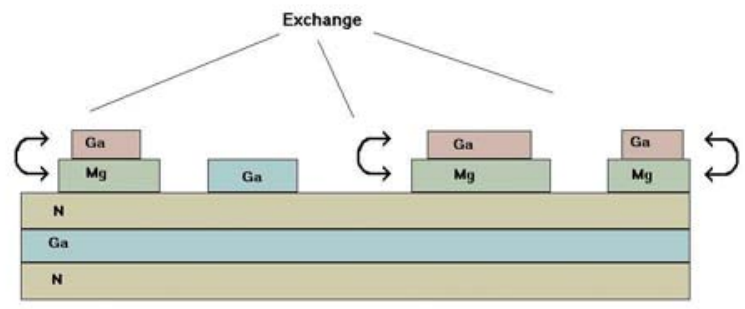

Figure 1a. A schematic picture depicting the incorporation of Ga by $\mathrm{Mg}$ and $\mathrm{N}$ described in 2.2 .

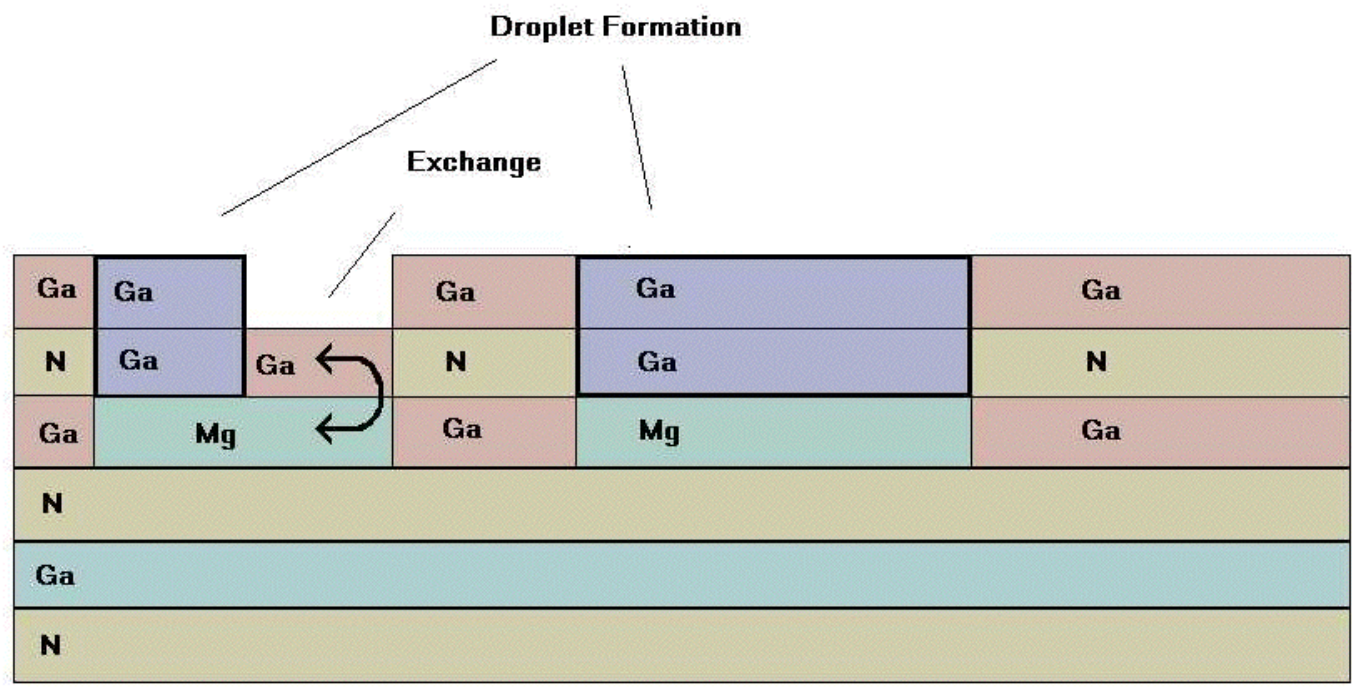

Figure 1b. A schematic picture depicting the formation of Ga droplets due to excess Ga arriving on surface described in section 2.2 . 
Two Competing Surface Processes

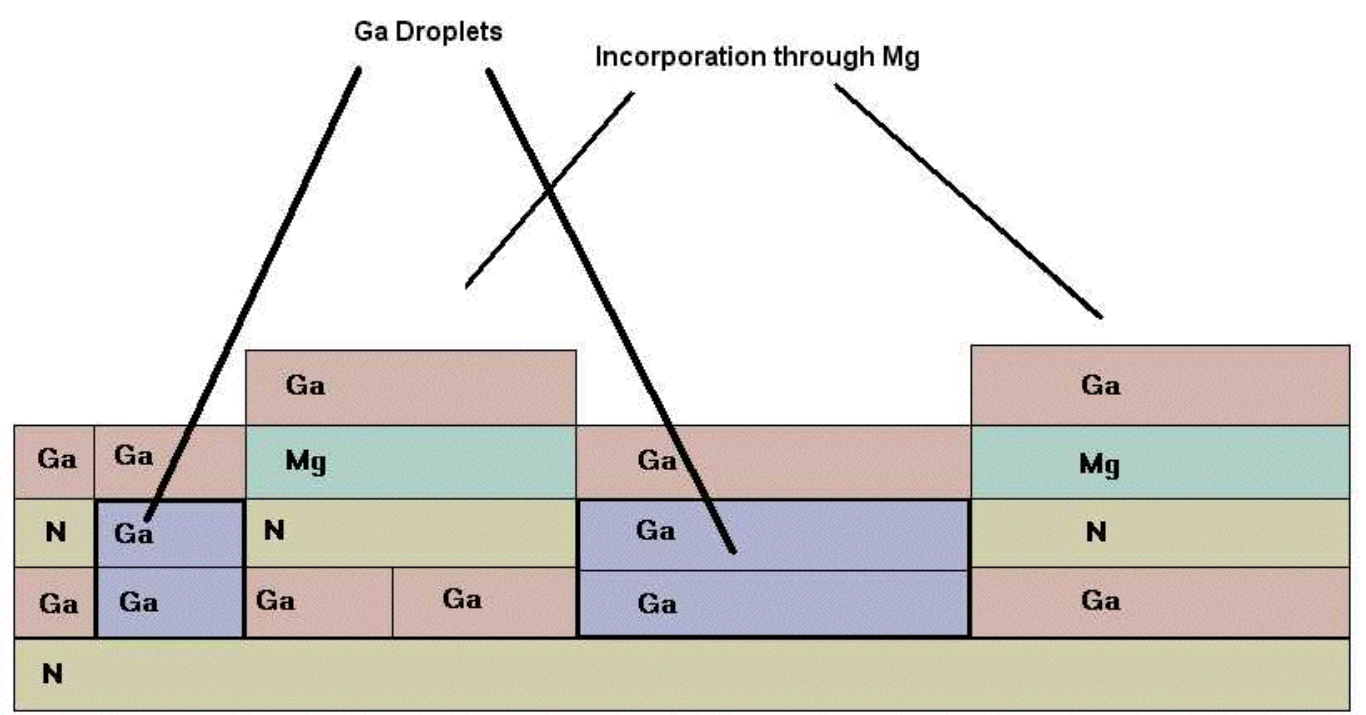

Figure 1c. A schematic picture depicting the segregation of $\mathrm{Mg}$ to the surface due to strain forcing $\mathrm{Mg}$ to migrate to the surface and two competing surface processes described in 2.2 .

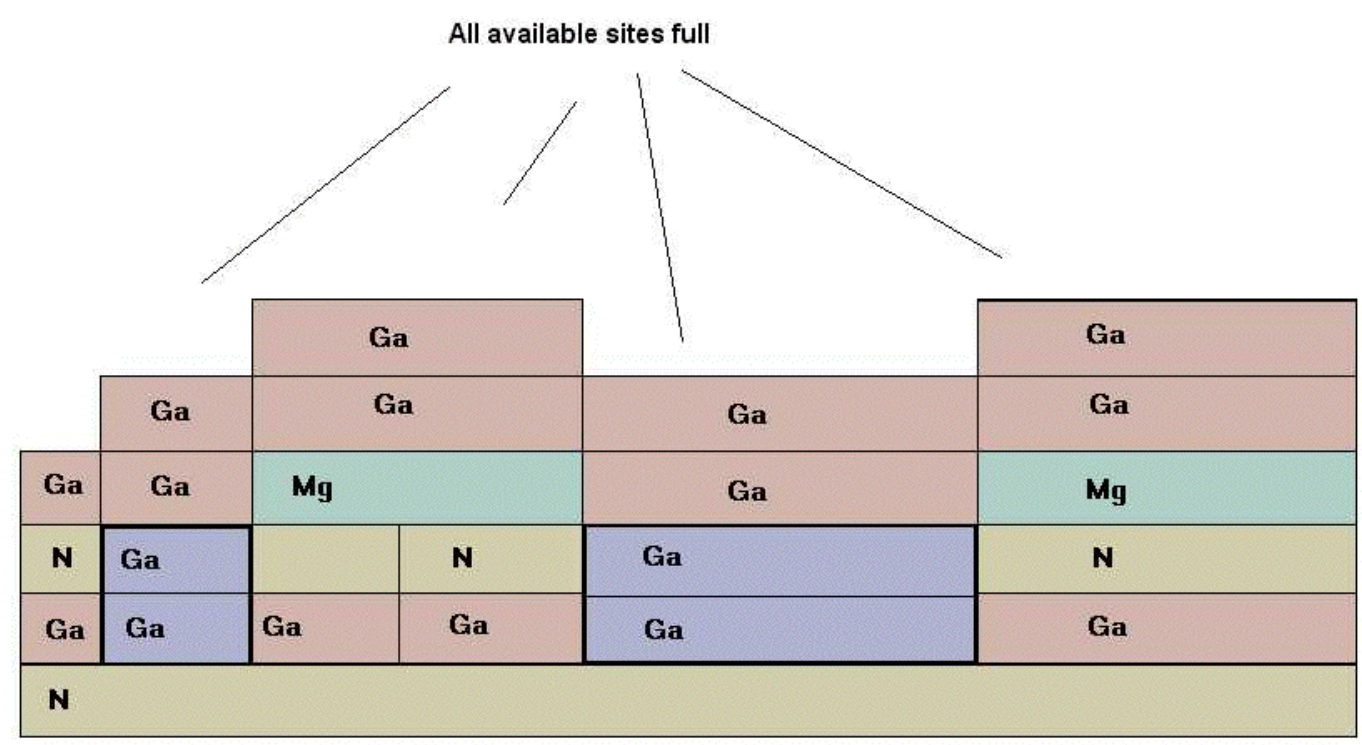

Figure 1d. A schematic picture depicting the surface processes resulting in growth rate saturation described in 2.2. 


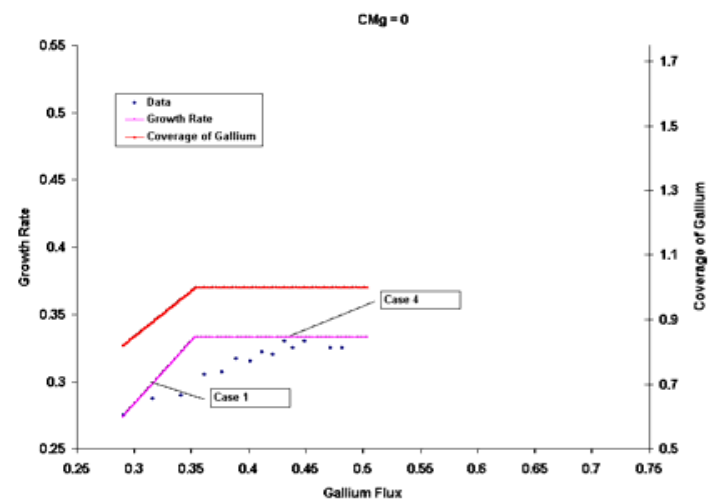

Figure 2. Calculated and experimental growth rate versus $\mathrm{Ga}$ flux for the $\mathrm{T}_{\mathrm{Mg}}$ cell temperature of $0^{\circ} \mathrm{C}$ corresponding to a $\mathrm{C}_{\mathrm{Mg}}$ of 0 . Coverage of Ga plotted as well.

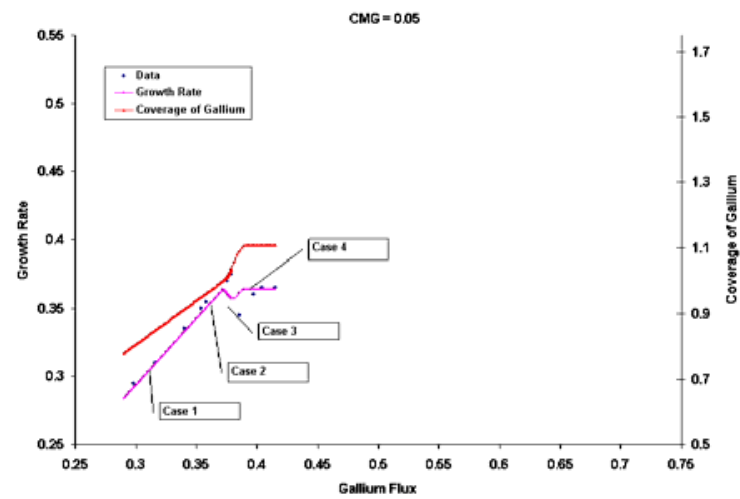

Figure 3. Calculated and experimental growth rate versus Ga flux for residual $\mathrm{Mg}$ in the MBE system corresponding to a $\mathrm{C}_{\mathrm{Mg}}$ of 0.05 . Coverage of Ga plotted as well.

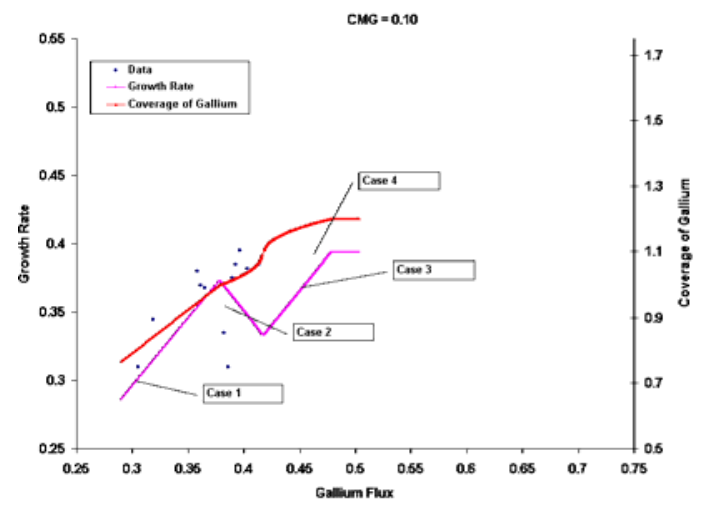

Figure 4. Calculated and experimental growth rate versus $\mathrm{Ga}$ flux for the $\mathrm{T}_{\mathrm{Mg}}$ cell temperature of $212^{\circ} \mathrm{C}$ corresponding to a $\mathrm{C}_{\mathrm{Mg}}$ of 0.10 . Coverage of Ga plotted as well.

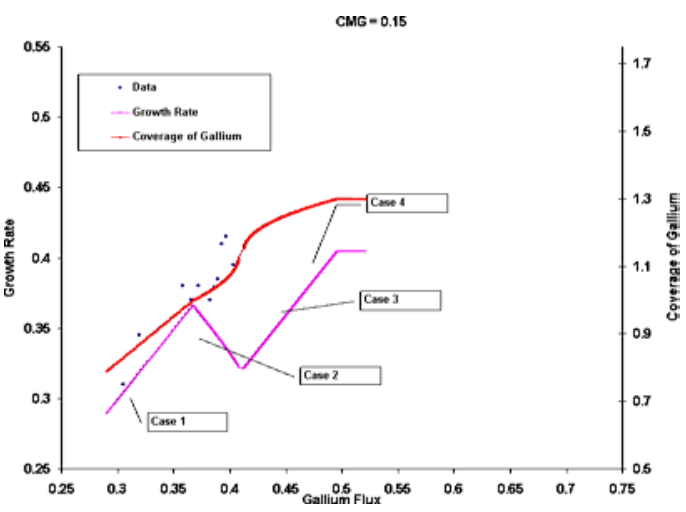

Figure 5. Calculated and experimental growth rate versus $\mathrm{Ga}$ flux for the $\mathrm{T}_{\mathrm{Mg}}$ cell temperature of $220^{\circ} \mathrm{C}$ corresponding to a $\mathrm{C}_{\mathrm{Mg}}$ of 0.15 . Coverage of Ga plotted as well.

\section{TABLES}

Table 1. Dependence of the various $\tau$ 's on the Mg Surface Coverage.

\begin{tabular}{|l|l|l|l|l|}
\hline CMg (ML) & 0 & 0.05 & 0.1 & 0.15 \\
\hline$\tau_{1}$ (s) & 3 & 2.53 & 2.43 & 2.25 \\
\hline$\tau_{2}$ (s) & 0 & 0.35 & 0.25 & 0.5 \\
\hline $\begin{array}{l}\text { Case 3 } \\
\text { multiplier }\end{array}$ & 1 & 1 & 0.667 & 0.541 \\
\hline$\tau_{3 \quad(s)}$ & 50 & 150 & 200 & 750 \\
\hline$\tau_{4 \quad(s)}$ & 0 & 15 & 5 & 4.75 \\
\hline $\begin{array}{l}\text { Case 3 } \\
\text { multiplier }\end{array}$ & 1 & 0.0105 & 0.025 & 0.0526 \\
\hline
\end{tabular}

